\title{
POR UM ATIVISMO PRÓ-SUSTENTABILIDADE
}

\author{
FOR A PRO-SUSTAINABILITY ACTIVISM \\ POR UN ACTIVISMO PRO-SOSTENIBILIDAD
}

Luciana Costa Poli ${ }^{1}$

\section{RESUMO}

O trabalho examina o fenômeno do ativismo judicial no contexto do Estado Democrático de Direito, abordando a importância da atuação do juiz para efetivação dos princípios constitucionais. O estudo destaca que essa atuação hoje se mostra complexa, em razão da grande mobilidade do sistema jurídico, garantida, especialmente, pela presença de cláusulas gerais de conteúdo aberto e fluido no ordenamento. A partir desta constatação, o trabalho propõe-se a analisar se esse fenômeno pode contribuir para as metas de sustentabilidade propostas pelo Estado. Verificando a existência de diversas nuances da sustentabilidade, procurar-se-á demonstrar que a sustentabilidade não se encerra em um conteúdo destituído de normatividade, ao contrário, pode ser compreendida como um princípio geral e sistêmico, orientador das decisões judiciais. Nesse sentido, defender-se-á que a atuação do juiz hoje deve ser politizada e conectada à satisfação dos objetivos de um Estado comprometido com a implementação do princípio da sustentabilidade.

PALAVRAS-CHAVE: Ativismo judicial. Cláusulas Gerais. Sustentabilidade. Meio Ambiente.

\begin{abstract}
The paper examines the phenomenon of judicial activism in the context of the Democratic State of Law, addressing the importance of the role of the judge for enforcing the constitutional principles. The study emphasizes that this role, nowadays, is complex due to the great mobility of the juridical system, guaranteed, especially, by the presence in the system of general clauses with open and fluid content. Based on this evidence, the paper examines whether this phenomenon can contribute to the sustainability goals proposed by the State. Noting the existence of various nuances of sustainability, it seeks to demonstrate that sustainability does not end in a content devoid of normativity, but rather, can be understood as a general and systemic principle that guides the judgments. In this sense, it defends the view that the role of the judge today must be politicized and connected to the satisfaction of the goals of a State that is committed to implementing the principle of sustainability.
\end{abstract}

KEYWORDS: Judicial Activism. General Clauses. Sustainability. Environment.

\section{RESUMEN}

Este trabajo examina el fenómeno del activismo judicial en el contexto del Estado Democrático de Derecho, abordando la importancia de la actuación del juez para la efectivación de los principios constitucionales. El estudio destaca que esa actuación actualmente se muestra compleja en razón de la gran movilidad del

1 Mestra em Direito e Instituições Políticas pela Universidade FUMEC/MG. Doutora em Direito Privado pela PUC-MINAS. Professora de Direito Civil na Escola Superior Dom Helder Câmara (Belo Horizonte/MG Brasil) e na Faculdade Estácio de Sá (Belo Horizonte/MG - Brasil). E-mail: lucostapoli@yahoo.com.br. 
sistema jurídico, garantizada, especialmente, por la presencia de cláusulas generales de contenido abierto y fluido en el ordenamiento. A partir de esa constatación, el trabajo se propone analizar si ese fenómeno puede contribuir con las metas de sostenibilidad propuestas por el Estado. Verificando la existencia de diversos matices en la sostenibilidad, se intentará demostrar que la sostenibilidad no se cierra en un contenido destituido de normatividad, sino que, por el contrario, puede ser comprendida como un principio general y sistémico, orientador de las decisiones judiciales. En este sentido se defenderá que la actuación del juez, en la actualidad, debe ser politizada y conectada a la satisfacción de los objetivos de un Estado comprometido con la implementación del principio de la sostenibilidad.

PALABRAS CLAVE: Activismo judicial. Cláusulas Generales. Sostenibilidad. Medio Ambiente.

\section{INTRODUÇÃO}

A partir da percepção do envolvimento e do posicionamento do Poder Judiciário em temas controversos e polêmicos que têm, de certa forma, contribuído para moldar o pensamento jurídico do país, propõe-se estudar o fenômeno do ativismo judicial e a sua importância para efetivação de princípios e valores caros ao Estado contemporâneo. Ao mesmo tempo, constata-se que a temática da sustentabilidade, na concepção principiológica que se apresenta neste trabalho, embora presente na ordem do dia, ainda carece de implementação efetiva.

Com isso, o estudo pretende demonstrar que a participação do Poder Judiciário, por meio de decisões que imprimam efetividade ao primado principiológico proposto pela Constituição da República de 1988 - em especial, o princípio da sustentabilidade -, é legítima, necessária e útil. Para tal fim, o trabalho se propõe inicialmente a analisar o ativismo judicial, compreendido como uma participação mais ativa e politizada do Poder Judiciário.

Percebe-se que, com a inclusão de cláusulas gerais de conteúdo aberto e fluido no ordenamento jurídico, como ocorre com o Código Civil de 2002, o juiz passou a receber do próprio legislador instrumentos para que trabalhe a construção de uma decisão mais coerente com a implementação dos valores e dos princípios perseguidos pelo Estado Democrático de Direito.

Partindo dessa visão, procura-se demonstrar que o direito na pós-modernidade abandonou o modelo positivista, que transformava os juízes em meros executores da lei, e passou a exigir uma maior participação do Poder Judiciário como corresponsável pela construção de uma sociedade que, de fato, pretenda alcançar os ideais do Estado de Direito. Sustenta-se que o ativismo judicial é uma ferramenta importante para que se possa extrair o máximo das potencialidades das linhas diretrizes do texto constitucional, privilegiando a busca de soluções mais adequadas para cada caso concreto.

A sustentabilidade, segundo a concepção que se apresentará, refere-se à busca do equilíbrio em qualquer esfera do desenvolvimento, seja ele econômico, político ou social. Assim, passa a ser vista como uma preocupação para com as gerações futuras, no sentido de que se relaciona intimamente com a forma de desenvolvimento da sociedade e dos seus impactos no entorno. Parte-se, portanto, da noção de que o desenvolvimento sustentável é aquele que pretende atender às necessidades do presente sem comprometer as possibilidades de gerações futuras.

Procurar-se-á constatar que o Estado Democrático de Direito não mais permite uma postura desidiosa e passiva do Judiciário, sendo que o juiz deve concretizar o significado dos princípios e, por conseguinte, do conteúdo da sustentabilidade, buscando dar-Ihe densidade real e concreta. 0 juiz, atento às demandas no mundo contemporâneo, não deve, ao julgar o caso, apenas aplicar o comando da lei, mas, sim, avaliar e sopesar os impactos de sua decisão na sociedade.

Defender-se-á que a sustentabilidade não pode ser concebida como mera opção. Ao contrário, deve ser adotada como orientação necessária e irrefutável para a conservação de mais capital natural para futuras gerações e, portanto, todos os mecanismos para sua implementação devem ser utilizados. 


\section{ATIVISMO JUDICIAL E CLÁUSULAS GERAIS}

A fim de atingir as metas propostas pelo Estado, torna-se fundamental a tarefa do julgador de contribuir para a construção de uma sociedade voltada à satisfação dos princípios e dos objetivos previstos no ordenamento constitucional. Essa visão pretende romper com o hermetismo técnicojurídico da mera subsunção do caso concreto às regras legais e a compreender o fenômeno jurídico como fenômeno social importante que deve servir como instrumento, ou um meio (não um fim), para a realização dos próprios valores perseguidos pelo Estado.

Tem-se denominado ativismo judicial a participação mais abrangente e intensa do Judiciário na concretização dos valores e fins constitucionais, mais especialmente de metas ambientais e de sustentabilidade, por meio da atuação que, de certa forma, demonstra uma maior interferência no espaço dos demais Poderes.

Esse instituto, segundo Barroso ${ }^{2}$, associa-se à postura ativista do juiz, que se manifesta por meio de condutas diversas, que incluem:

(i) a aplicação direta da Constituição a situações não expressamente contempladas em seu texto e independentemente de manifestação do legislador ordinário; (ii) a declaração de inconstitucionalidade de atos normativos emanados do legislador, com base em critérios menos rígidos que os de patente e ostensiva violação da Constituição; (iii) a imposição de condutas ou de abstenções ao Poder Público, notadamente em matéria de políticas públicas.

A atuação do Poder Judiciário ganha, dessa forma, um relevo que passa a ser compreendido como necessário ao processo de implementação das políticas públicas e dos valores e dos princípios pretendidos pela Constituição da República de 1988.

Relaciona Barroso ${ }^{3}$ que o oposto do ativismo é a denominada autocontenção judicial, conduta pela qual o Judiciário procura reduzir sua interferência nas ações dos outros Poderes. Por essa linha, juízes e tribunais (i) evitam aplicar diretamente a Constituição a situações que não estejam no seu âmbito de incidência expressa, aguardando o pronunciamento do legislador ordinário; (ii) utilizam critérios rígidos e conservadores para a declaração de inconstitucionalidade de leis e atos normativos e (iii) abstêm-se de interferir na definição das políticas públicas.

Partindo dessas noções preliminares, parece claro que, até o advento da Constituição de 1988, essa era a inequívoca linha de atuação do Poder Judiciário no país.

Em princípio, o ativismo judicial pretende extrair o máximo das potencialidades das linhas diretrizes do texto constitucional, privilegiando a busca de soluções para o caso concreto que se coadunem com a principiologia a ser implementada pelo Estado Democrático de Direito.

A autocontenção parece ensejar a ideia de que, ao limitar a atuação dos juízes, restringe a própria aplicação imediata e direta da Constituição, já que, no silêncio da lei para a solução do caso, demandaria o aguardo do pronunciamento do legislador.

Ao que tudo indica, o próprio Poder Legislativo tem dado impulso ao movimento ativista. Tal prática é perceptível nas próprias diretrizes introduzidas no ordenamento civil, com o advento do Código Civil de 2002, o qual foi erigido por inúmeras cláusulas gerais.

2 BARROSO, Luís Roberto. Judicialização, ativismo judicial e legitimidade democrática. Revista de Direito do Estado, Rio de Janeiro, n. 13, jan./mar. 2009, p. 75.

3 BARROSO, Luís Roberto. Judicialização, ativismo judicial e legitimidade democrática. Revista de Direito do Estado, Rio de Janeiro, n. 13, jan./mar. 2009, p. 76. Segundo o autor, o ativismo teve origem na jurisprudência norte-americana, mas, em um primeiro momento, de natureza conservadora. Foi na atuação proativa da Suprema Corte que os setores mais reacionários encontraram amparo para a segregação racial (Dred Scott $v$. Sanford, 1857) e para a invalidação das leis sociais em geral (Era Lochner, 1905-1937), culminando no confronto entre o Presidente Roosevelt e a Corte, com a mudança da orientação jurisprudencial contrária ao intervencionismo estatal (West Coast v. Parrish, 1937). A situação se inverteu completamente a partir da década de 50, quando a Suprema Corte, sob a presidência de Warren (1953-1969) e nos primeiros anos da Corte Burger (até 1973), produziu jurisprudência progressista em matéria de direitos fundamentais, sobretudo envolvendo negros (Brown v. Board of Education, 1954), acusados em processo criminal (Miranda v. Arizona, 1966) e mulheres (Richardson v. Frontiero, 1973), assim como no tocante ao direito de privacidade (Griswold v. Connecticut, 1965) e de interrupção da gestação (Roe v. Wade, 1973). 
A cláusula geral apresenta características de generalidade e abstração, permitindo ao intérprete a construção de uma decisão calcada em princípios considerados relevantes na solução do caso concreto. Além disso, também é um instrumento pelo qual o Estado, por meio do Poder Judiciário, aumenta sua interferência na economia e nas relações negociais.

Dessa forma, a atuação do juiz ganha complexidade e importância, passando a usufruir de grande abertura e mobilidade, permitindo-Ihe a construção de uma solução que absorva o conteúdo principiológico de todo o sistema jurídico, abandonando a aplicação fria e distante do texto puramente legal ao caso concreto. De acordo com Jorge Junior ${ }^{4}$ :

\begin{abstract}
Transitando entre a generalidade, a vagueza e os valores, inseridas numa roupagem de proposição prescritiva escrita, as cláusulas gerais afirmam o objetivo de dotar o sistema de normas com características de mobilidade, que propiciem abertura ao ordenamento jurídico, evitando-se a tensão entre preceitos normativos rígidos e valores em mutação a implicar um indesejável malestar decorrente de um embate sem solução sistêmica. Seria, ademais, o alto teor valorativo nas cláusulas gerais o elemento caracteristicamente diferenciador destas normas perante o ordenamento jurídico, o nódulo essencial que faria com que as cláusulas gerais fossem aquilo que são.
\end{abstract}

Submetem-se, assim, os julgados a princípios éticos e solidaristas perseguidos pela Carta Magna, pois as cláusulas gerais, quando inseridas na lei, refletem esses ideais. Nessa conformação, o Código Civil estabelece diversas cláusulas gerais, tais como a boa-fé objetiva, a responsabilidade pelo dano, o enriquecimento ilícito e a função social do contrato, que irão permitir que a decisão sobre tais institutos atenda a valores não apenas econômicos e individualistas, mas éticos e solidários.

É inegável que a lógica e o perfil do sistema foram invertidos. De um sistema fechado, no qual se identificava o dogma do Direito-Lei, passa-se a um sistema aberto, de autorreferência relativa, que reclama novas soluções, uma nova hermenêutica e desafia o intérprete.

Diferentemente de outras normas, as cláusulas gerais introduzem a ideia de que o juiz, ao buscar solucionar o caso, seleciona certos fatos ou comportamentos para confrontá-los com um determinado parâmetro, orientado pela busca de implementação dos objetivos do Estado. Certo é que a decisão a ser emitida não se conformará a uma solução predeterminada. De certa forma, o juiz ganha um poder extraordinariamente amplo. "Não apenas estará estabelecendo o significado do enunciado normativo, mas acaba criando direito, ao completar a fattispecie e ao determinar ou graduar as consequências"'.

A crescente inclusão de cláusulas gerais no ordenamento conduz à conclusão de que o direito não é originado somente pelo que preceitua o legislador. Mais que isso, é um produto das experiências, dos fatos e dos costumes da sociedade, de modo que imaginar um direito pleno, baseado no centralismo jurídico e com todas as condutas-tipo ${ }^{6}$ previstas, facilmente o torna obsoleto. Menezes Cordeiro 7 , ao abordar a adequação da amplitude semântica (para o direito acompanhar o fato social), prevê que "ainda quando a lei não reaja, a ordem jurídica deve fazêIo". Nas palavras de Canaris ${ }^{8}$, o ideal seria que, para acompanhar a evolução social, o sistema legal fosse dotado da ideia de incompletude.

Essa noção de incompletude do sistema revela que não se deve esperar do Poder Legislativo a solução para todas as situações concretas enfrentadas pela sociedade. Ao contrário, talvez seja o momento de admitir que o Poder Judiciário tem papel decisivo na implementação de um Estado comprometido com as metas constitucionais. Isso denota também que, ao acompanhar o caso concreto, o magistrado está mais próximo dos dilemas e dos problemas sociais e, portanto, mais apto a concretizar as escolhas constitucionais de modo a coaduná-las com os interesses das partes.

4 JORGE JUNIOR, Alberto Gosson. Cláusulas gerais no novo código civil. São Paulo: Saraiva, 2004, p. 10.

5 MARTINS-COSTA, Judith. A boa-fé no direito privado: sistema e tópica no processo obrigacional. São Paulo: Editora Revista dos Tribunais, 1999, p. 130.

6 É a técnica da fattispecie, comumente usada na época da codificação, que visava reduzir a margem interpretativa do aplicador de direito, revestindo a norma de imutabilidade, garantindo a segurança jurídica (IRTI, Natalino. L'età della decodificazione. 4. ed. Milano: Giufrrè, 1999, p. 20).

7 MENEZES CORDEIRO, Antônio Manuel da Rocha e. Da boa-fé no direito civil. Coimbra: Almedina, 2001, p. 46.

8 CANARIS, Claus-Wilheim. Pensamento sistemático e conceito de sistema na ciência do direito. 2. ed. Lisboa: Fundação Calouste Gulbenkian, 1996, p. 24. 


\section{A COMPATIBILIDADE DO ATIVISMO JUDICIAL NA ESTRUTURA DO PODER JUDICIÁRIO NO CONTEXTO DO ESTADO DEMOCRÁTICO DE DIREITO}

A alteração de paradigmas, necessária para o desenvolvimento da ciência jurídica, pode ser sentida de modo bastante contundente na própria finalidade do Estado Contemporâneo. O sistema jurídico, que marcava o liberalismo, consagrava como vértice a proteção a metas individuais de aquisição e acumulação de bens, resguardadas pelas leis civilistas de proteção à propriedade e ao contrato.

Mas, além das alterações políticas e sociais que culminaram com o fim do modelo clássico, as incansáveis e prejudiciais interferências do homem no planeta trouxeram mudanças significativas ao meio ambiente, levando o Estado a repensar os seus próprios fins. Adverte Canotilho ${ }^{9}$ que o Estado passa a assumir o dever de defender a natureza e o ambiente, preservar os recursos naturais e assegurar um correto ordenamento territorial. Tais tarefas, prossegue o autor, enquadradas em ordenamentos jurídicos de vários países como princípios fundamentais, transformam o Estado de direito em Estado democrático-ambiental, ao admitir o direito ao ambiente como seu fim ${ }^{10}$.

A teoria clássica da separação de poderes foi concebida para atribuir existência e limites a cada órgão do Estado, na medida em que no contexto absolutista da época era necessária uma oposição à autoridade centralizada e arbitrária. O cerne da construção dessa teoria baseia-se na separação das funções políticas e do direito, o que culminou, de certa forma, na neutralização da política no exercício da atividade jurisdicional. A divisão do poder do Estado em duas funções principais - criação e aplicação do direito - correspondia à ideia da inibição recíproca, a fim de se coibir o exercício do poder de forma ilimitada e absoluta. Impedia-se, assim, a superposição de um em relação aos outros.

Neste contexto, o Poder Judiciário orientava suas ações observando o princípio da estrita legalidade, o que transformou a aplicação do direito em subsunção racional-formal dos fatos às normas, divorciada de quaisquer referências políticas ou valorativas. Essa postura ideológica de total vinculação do juiz aos ditames legais não considerava os ideais de justiça substancial e do próprio direito, gerando a errônea impressão de que o magistrado não podia ser politizado, sob pena de afastar-se dos postulados da época ${ }^{11}$. O Poder Judiciário tornou-se introspectivo e retroativo, já que se destinava tão somente a garantir aplicação da lei de modo a reconstituir determinadas situações que não se coadunavam com as normas preestabelecidas.

A ideia de que a prestação jurisdicional deveria corresponder aos ditames já consagrados pelo ordenamento legal eleva o princípio da segurança jurídica, como dogma, de forma a não admitir soluções para o caso concreto que não estivessem na lei. A atuação dos magistrados era confinada aos limites do litígio interindividual, assinalando a ideologia individualista que marcou o início da era moderna.

O distanciamento entre a prestação jurisdicional e as novas demandas e expectativas sociais refletia a ausência de oxigenação do sistema jurídico, que arraigado pelo ideal positivista refletia, ao reproduzir fielmente o direito positivo, uma distorção entre a realidade e a decisão proferida.

As insuficiências desse modelo logo surgiram com a perda da certeza de que todas as respostas às demandas estariam na lei. Passa-se a compreender a ciência do direito como ciência de compreensão hermenêutica ${ }^{12}$, abandonando-se o paradigma dogmático. Nesse sentido, Souza ${ }^{13}$ afirma que, para regular a contingência e a diversidade do sistema social, faz-se necessário transcender os meros limites da dedução, reconhecendo que as normas haverão de ceder espaço

9 CANOTILHO, José Joaquim Gomes. Protecção do ambiente e direito de propriedade: crítica de jurisprudência ambiental. Coimbra: Coimbra Editora, 1995, p. 13.

10 CANOTILHO, José Joaquim Gomes. Protecção do ambiente e direito de propriedade: crítica de jurisprudência ambiental. Coimbra: Coimbra Editora, 1995, p. 81 e 93.

11 PODESTÁ, Fábio Henrique. A ideologia das decisões judicias em matéria de contratos. In: HIRONAKA, Giselda Maria Fernandes Novaes. A outra face do judiciário: decisões inovadoras e mudanças de paradigmas. Belo Horizonte: Editora Del Rey, 2005, p. 163.

12 SILVA, Ovídio A. Baptista da. Processo e Ideologia: o paradigma racionalista. Rio de Janeiro: Forense, 2004, p. 22.

13 SOUZA, Luiz Sérgio Fernandes de. O papel das ideologias no preenchimento das lacunas de direito. São Paulo: RT, 1993, p. 112. 
aos princípios, mais flexíveis, rompendo a clausura imposta pela era da codificação. A dogmática jurídica há de ser vista como ciência interpretativa de caráter funcional, na medida em que o juiz passa a operar pautado em valores ${ }^{14}$ e princípios, voltados à concretização de determinados fins considerados socialmente relevantes.

A higidez do sistema jurídico e a sua contínua evolução dependem da abertura do sistema jurídico. A ciência do Direito, como toda ciência, depende de mobilidade que se perfaz por constantes rupturas de paradigmas e pela aceitação de novas ideologias.

O Estado Democrático de Direito requer um abandono da postura distante do Poder Judiciário, reclamando uma postura ativa e participativa na concretização das políticas sociais e dos objetivos da República. A atuação do juiz passa a ser fundamental na sedimentação de uma pauta de princípios e valores que se orientam para a construção de um Estado voltado a metas de implementação de crescimento sustentável.

Atribuir a implementação dessas metas apenas aos demais poderes é sujeitar-se à instabilidade temporal típica do momento político, ao conflito de interesses e à malversação tão inerente ao Poder Legislativo, o que torna de extrema importância a função judicial como voz ativa na criação do Direito ${ }^{15}$.

O papel de juiz é vital para que se confira efetividade à carta de princípios do Estado Democrático, compatibilizando, no caso concreto, os direitos individuais e os fins do Estado, apregoando não apenas o solidarismo, mas propiciando o desenvolvimento sustentável de quaisquer políticas públicas. Assim, perfeitamente lícita e eficaz será a intervenção do Judiciário como forma de conferir o necessário equilíbrio das relações privadas às metas de sustentabilidade. Adverte-se:

Não no sentido pejorativo do juiz criar o Direito, de decisão extralegal de ditadura do Poder Judiciário ou qualquer outro epíteto semelhante que se queira atribuir, nem no sentido da utilização exclusiva da jurisprudência como fonte de direito, mas no sentido do juiz vivificar no caso concreto, a norma abstrata e estática posta pela lei ${ }^{16}$.

A adoção da principiologia constitucional pressupõe a repolitização do Poder Judiciário e do Direito, a preocupação com o conteúdo abstrato das normas, a aceitação do pluralismo jurídico e a legitimação das decisões fundamentadas não apenas na lei ${ }^{17}$.

O Estado Democrático de Direito mostra-se como um sistema aberto, que se alimenta também da atividade jurisdicional criadora, razão pela qual não pode a atuação do juiz ser trabalhada como mero ato mecânico de aplicação da lei, afinal, o sistema jurídico atual é dialético ${ }^{18}$. Nesse diapasão, a lógica da interpretação jurídica deve ser argumentativa e não dedutiva ${ }^{19}$.

Certo é que a solução dada a cada caso não poderá contrariar frontalmente o sistema vigente. Há limites à argumentação, limites esses que são pautados pelos direitos fundamentais ${ }^{20}$. A atividade do magistrado deve ser cautelosa e responsável, sob pena de desencadear um governo dos juízes, ou implementar juízes legisladores ${ }^{21}$.

14 LARENZ. Karl. Metodologia da ciência do direito. Lisboa: Fundação Calouste Gulbenkian, 1997, p. 312.

15 DEL NERO, João. Interpretação realista do direito e seus reflexos na sentença. São Paulo: RT, 1987, p. 48.

16 PODESTÁ, Fábio Henrique. A ideologia das decisões judicias em matéria de contratos. In: HIRONAKA, Giselda Maria Fernandes Novaes. A outra face do judiciário: decisões inovadoras e mudanças de paradigmas. Belo Horizonte: Editora Del Rey, 2005, p. 168.

17 AMARAL, Francisco. Transformações dos sistemas positivos a descodificação do direito civil brasileiro. O Direito, Lisboa, ano 129, v. I, n. II, 1997, p. 44-45.

18 LORENZETTI, Ricardo Luis. Fundamentos do direito privado. Tradução Vera Maria Jacob de Fradera. São Paulo: Revista dos Tribunais, 1998, p. 79.

19 FIÚZA, César. Crise e interpretação do direito civil da escola da exegese às teorias da argumentação. In: FIÚZA, César; SÁ, Maria de Fátima Freire de; NAVES, Bruno Torquato de Oliveira (Coords.). Direito civil: atualidades. Belo Horizonte: Editora Del Rey, 2004, p. 33.

20 LEAL, Rosemiro Pereira. Teoria processual da decisão jurídica. São Paulo: Landy, 2002, p. 148149.

21 CAPELLETTI, Mauro. Juízes legisladores? Tradução de Carlos Alberto Álvaro de Oliveira. Porto Alegre: Sergio Antônio Fabris Editor, 1999, p. 15. 
O espaço normativo da interpretação jurídica pressupõe a legitimação da norma criada. Assim, na lição de Leal22, a decisão, na democracia juridicamente institucionalizada, não pode preterir os direitos fundamentais, que funcionam como verdadeiros limites à atividade interpretativa e não apenas elementos constitucionais de construção hermenêutica. Para tanto, prossegue o autor, faz-se necessária a transição da concepção do Estado como entidade, para a concepção de Estado como espaço processualmente demarcado à discursividade: produção, recriação e aplicação dos direitos positivados.

Em um sistema aberto-problemático, a construção da norma será a partir da interpretação do sistema jurídico, de seus princípios, valores e regras, e sua consequente aplicação à realidade fáticojurídica ${ }^{23}$. A legitimidade do processo jurisdicional "criativo" se dará na construção argumentativa da aplicação dos princípios. A norma é o sentido que se pode encontrar em um costume ou em um texto normativo, atribuído por meio da argumentação jurídica, que não se revela pela discricionariedade do juiz no julgamento do caso concreto, mas pressupõe a existência de uma comunidade (jurídica) linguisticamente estruturada, o que significa que este sentido é atribuído por intermédio do discurso e da universalização ${ }^{24}$.

Os fundamentos do Estado Democrático de Direito devem ser vistos como princípios normativos, "meios lógico-jurídicos positivados no instrumento constitucional"25, que não podem ser preteridos na atividade jurisdicional, mas que a atividade do juiz não dever refletir apenas valores ou "ideário de artifícios para decisões prodigiosas" 26 . A intervenção estatal não pode ser justificada apenas pelo controle estatal, a intervenção pode e deve ser promocional.

A interpretação da norma de forma a aproximar-se do princípio por ela fixado não é opção, mas pressuposto de legitimidade da solução jurídica. Assim, o princípio da funcionalidade do direito subjetivo é o elemento legitimador da própria regra, de forma que o que vem explícito no princípio vem implícito na regra. Assim, o princípio deve ser observado pelo jurista, pelo juiz e pelo legislador ${ }^{27}$.

A implementação de metas de sustentabilidade se dará, no caso concreto, na vinculação do sistema jurídico a partir do problema ${ }^{28}$, considerando-se que sempre haverá uma pluralidade de soluções para o litígio. Não se pode olvidar que os efeitos jurídicos produzidos pela decisão terão direto impacto na realidade fática. Nesse quadro, não é satisfatório ou suficiente que a decisão seja coerente apenas no âmbito do sistema jurídico, deve ser adequada em relação às consequências produzidas, ou que irá produzir, no mundo real ${ }^{29}$.

O paradigma do Estado Democrático de Direito pressupõe que o Judiciário retrabalhe construtivamente os princípios e as regras do sistema para que possa satisfazer, cumulativamente, a exigência de reforçar a crença na legalidade entendida como segurança jurídica e o sentimento de justiça realizada, que se dará pela adequabilidade da decisão às particularidades do caso concreto ${ }^{30}$.

A intensidade dos problemas planetários na contemporaneidade requer respostas rápidas e adequadas. Há que se construir uma perspectiva de conformação do direito ajustado às demandas desses novos tempos. Não basta apenas concebê-lo como instrumento de pacificação dos conflitos, como sistema ou ordenamento de normas jurídicas estáticas que objetivam assegurar direitos e

22 LEAL, Rosemiro Pereira. Teoria processual da decisão jurídica. São Paulo: Landy, 2002, p. 152.

23 SÁ, Maria de Fátima Freire de. Direito de morrer. Belo Horizonte: Del Rey, 2001.

24 GALUPPO. Marcelo Campos. Os princípios jurídicos no Estado Democrático de Direito: ensaio sobre o modo de sua aplicação. Revista de Informação Legislativa. Brasília, a.36, n. 143, jul./set. 1999, p. 208.

25 LEAL, Rosemiro Pereira. Isonomia processual e igualdade fundamental a propósito das retóricas ações afirmativas. Revista Jurídica Unijus, Uberaba, v. 6, 2003, p. 47.

26 LEAL, Rosemiro Pereira. Isonomia processual e igualdade fundamental a propósito das retóricas ações afirmativas. Revista Jurídica Unijus, Uberaba, v. 6, 2003, p. 47.

27 LORENZETTI, Ricardo Luis. Fundamentos do direito privado. Tradução Vera Maria Jacob de Fradera. São Paulo: Revista dos Tribunais, 1998, p. 253.

28 VIEHWEG, Theodor. Tópica e jurisprudência. Brasília: Imprensa Nacional, 1979, p. 99.

29 FIÚZA, César. Crise e interpretação do direito civil da escola da exegese às teorias da argumentação. In: FIÚZA, César; SÁ, Maria de Fátima Freire de; NAVES, Bruno Torquato de Oliveira (Coords.). Direito civil: atualidades. Belo Horizonte: Editora Del Rey, 2004, p. 55.

30 CARVALHO NETTO, Menelick de. Requisitos pragmáticos da interpretação jurídica sob o paradigma do estado democrático de direito. Revista de Direito Comparado, Belo Horizonte, v. 3. 1999, p. 473-486. 
exigir o cumprimento dos deveres. Deve-se pensá-lo como um processo sociocultural de promoção, regulação e garantia das conquistas já obtidas também para as próximas gerações.

\section{SUSTENTABILIDADE: NOÇÕES GERAIS}

Todas as ciências são constantemente desafiadas por novas situações que levam a quebra dos paradigmas, marcando o violento choque entre teorias e ideais. Dessas discussões, teorias consagradas cedem lugar às ideias nunca antes concebidas e à busca de novos ideais. Assim é a ciência jurídica, principalmente na pós-modernidade, fase marcada pela renovação, desconstrução e consequente reconstrução de paradigmas.

A relevância das questões ambientais nos dias atuais é de ordem tal que não poderia deixar indiferentes o Estado e o Direito. Consequentemente, de forma paralela à juridicidade, à democracia, à socialidade, à eticidade, a sustentabilidade ambiental surge como uma das metas dos Estados Democráticos de Direito. Todavia a sustentabilidade é tema bastante amplo que não se encerra apenas em uma visão ambiental. Ao contrário, permeia toda a atividade humana.

A sustentabilidade pode ser compreendida como a busca do equilíbrio em qualquer esfera do desenvolvimento, seja ele econômico, político ou social. Engles ${ }^{31}$ deixa clara a correlação entre o aprimoramento da capacidade humana para transformar a natureza e o desenvolvimento de relações sociais mais complexas. A lógica humana, segundo se extrai do pensamento desse autor, parece sempre a mesma: utilizar os recursos naturais de maneira que melhor possa gerar benefícios materiais imediatos, a quem os explorasse, sem qualquer preocupação com os efeitos das ações humanas sobre o entorno.

O desenvolvimento das teorias e dos sistemas econômicos deu maior impulso a essa atitude e o capitalismo, ao apregoar a circulação e a acumulação de riquezas, acelerou o processo de ocupação territorial. $\mathrm{O}$ crescimento populacional e as novas demandas consumistas levaram à contratação em massa e, consequentemente, a utilização e o emprego dos recursos naturais se elevaram significativamente, trazendo impactos sem precedentes para o meio ambiente ${ }^{32}$.

A humanidade, dessa maneira, foi criando uma redoma de conveniências e comodidades, subjugando o ambiente natural e, ao mesmo tempo, tentando empurrá-lo a uma distância segura, como se de fato pudesse dele se desvincular ou distanciar. Assim, o desenvolvimento do arado e a domesticação dos animais levou o homem do nomadismo às primeiras experiências espaciais territoriais. Depois, o incremento das técnicas de agricultura, o aperfeiçoamento da tecnologia do maquinário e a larga utilização da energia aumentaram sobremaneira a produtividade e conduziram o homem à apropriação cada vez maior dos espaços, levando-o a lugares até então inacessíveis e confinando espécies de animais e plantas a territórios determinados e restritos.

A força onipresente da natureza, tão cara ao homem primitivo, tornou-se apenas uma referência longínqua para o homem da cidade que, na condução de suas máquinas ultramodernas, parecia ignorar os efeitos de sua existência inconsequente para o planeta.

Talvez a Conferência de Estocolmo de 1972 tenha sido um marco do despertar oficial para as necessidades de um planeta devastado pela exploração desmedida. A voracidade do crescimento descontrolado e a estupidez humana parecem ter colocado a própria existência em risco. Diante de um quadro de degradação do meio ambiente natural, o caos perpetrado pela humanidade na ocupação dos espaços acabou por engendrar um novo ideal, uma nova força que se converteria num verdadeiro mantra ambientalista: sustentabilidade ou desenvolvimento sustentável ${ }^{13}$.

A partir dessa noção, deve-se buscar conciliar as necessidades atuais do homem - e sua habilidade na exploração dos recursos naturais - com as necessidades das gerações futuras, o que se entende

31 ENGLES, Friedrich. A origem da família, da propriedade privada e do estado. Tradução Ruth M. São Paulo: Klauss Centauro Editora, 2009.

32 HANSEN, Gilvan Luiz. A sociedade de consumo e o paradoxo da proteção ambiental. In: FLORES, Nilton Cesar (Org.). A sustentabilidade ambiental em suas múltiplas faces. São Paulo: Editora Millennium, 2012.

33 Preocupação tão constante na atualidade que foi o foco da Conferência das Nações Unidas sobre Desenvolvimento Sustentável, a RIO+20, no mês de junho de 2012, na cidade do Rio de Janeiro/RJ. 
por responsabilidade intergeracional ${ }^{34}$. Tal tarefa revela-se, na prática, extremamente complexa, ainda que aparentemente lógica e irrefutável ${ }^{35}$. Nesse contexto, todos os atores sociais precisam se envolver conscientemente de modo a cooperar para a implementação de políticas de sustentabilidade.

Sustentabilidade é expressão polissêmica que tanto pode ser compreendida por meio de um conceito ecológico, a qual visa à capacidade de atender às necessidades de um grupo social no espaço que ocupa, bem como um conceito político, na qual a sociedade estabelece formas de organizar-se, delimitando seu crescimento, tendo em vista a observância das condições dos recursos naturais, dos meios tecnológicos e do nível efetivo ao bem-estar social.

Esse enfoque, no entanto, é insuficiente, pois a sustentabilidade comporta diversos outros fatores, com conceitos e características próprias - o que revela sua importância no contexto socioambiental:

\begin{abstract}
O conceito de sustentabilidade comportaria sete aspectos principais: (i) sustentabilidade social: melhoria da qualidade de vida da população, equidade na distribuição de renda e de diminuição das diferenças sociais, com participação e organização popular; (ii) sustentabilidade econômica: públicos e privados, regularização do fluxo desses investimento, compatibilidade entre padrões de produção e consumo, equilíbrio de balanço de pagamento, aceso á ciência e tecnologia; (iii) sustentabilidade ecológica: o uso dos recursos naturais deve minimizar danos aos sistemas de sustentação da vida: redução dos resíduos tóxicos e da poluição, reciclagem de materiais e energia, conservação, tecnologias limpas e de maior eficiência e regras para uma adequada proteção ambiental; (iv) sustentabilidade cultural: respeito aos diferentes valores entre os povos e incentivo a processos de mudança que acolham as especificidades locais; ( $v$ ) sustentabilidade espacial: equilíbrio entre o rural e o urbano, equilíbrio de migrações, desconcentração das metrópoles, adoção de praticas agrícolas mais inteligentes e não agressivas á saúde e ao ambiente, manejo sustentável das florestas e industrialização descentralizada; (vi) sustentabilidade política; no caso do Brasil, a evolução da democracia representativa para sistemas descentralizados e participativos, construção de espaços públicos comunitários, maior autonomia dos governos locais e descentralização da gestão de recursos; (vii) sustentabilidade ambiental: conservação geográfica, equilíbrio de ecossistemas, erradicação da pobreza e da exclusão, respeito aos direitos humanos e integração social ${ }^{36}$.
\end{abstract}

A noção de sustentabilidade, de certa forma, revela a expressão da crise cultural, civilizacional e espiritual que a humanidade atravessa. Capra ${ }^{37}$ já vislumbrava, nas últimas décadas do século XX, essa profunda crise mundial. Uma crise, segundo o autor, que afetaria todos os aspectos da vida humana - saúde, relações sociais, economia, tecnologia, direito e política. Uma crise de dimensões espirituais, intelectuais e morais, em tal escala que, pela primeira vez na história, a humanidade estaria sendo obrigada a se defrontar com a real ameaça de sua extinção e de toda a vida no planeta.

Esta crise direciona o homem a repensar seu posicionamento perante o planeta, obrigando-o a discutir sua real dimensão de responsabilidade perante tudo o que existe - e não apenas o seu entorno próximo - e, ainda, a responsabilizar-se diante daqueles que ainda nem existem.

Na obra de Jonas ${ }^{38}$, são encontrados caminhos para a formulação de uma ética da sustentabilidade fundada no princípio da responsabilidade. A responsabilidade, segundo o autor, está umbilicalmente ligada à sustentabilidade ao referir-se ao futuro longínquo da humanidade, estendendo-se até descendentes muito afastados no tempo, abarcando um futuro ilimitado. A responsabilidade para com as gerações vindouras não admite pausas, é contínua e perpétua.

34 Desenvolvimento sustentável é "aquele que atende as necessidades do presente sem comprometer as possibilidades de gerações futuras atenderem suas próprias necessidades" (BRUNDTLAND, Gro Harlem. Nosso futuro comum: comissão mundial sobre meio ambiente e desenvolvimento. 2. ed. Rio de Janeiro: Fundação Getúlio Vargas, 1991. Disponível em: <http://pt.scribd.com/doc/12906958/ Relatorio-Brundtland-Nosso-Futuro-Comum-Em-Portugues $>$. Acesso em: 8 mar. 2013). Trata-se, basicamente, da igualdade intergeracional.

35 CHALIFOUR, Nathalie J. Land use law for sustainable development. Cambridge University Press: Cambridge, 2007, p. 25.

36 FARIA, José Henrique de. Por uma teoria crítica da sustentabilidade. In: NEVES, Lafaiete Santos (Org.). Sustentabilidade: anais de textos selecionados do $\mathrm{V}$ seminário sobre sustentabilidade. Curitiba: Juruá Editora, 2011, p. 17.

37 CAPRA, Fritjof. O Ponto de mutação: a ciência, a sociedade e a cultura emergente. 25. ed. São Paulo: Cultrix, 1982, p. 19.

38 JONAS, Hans. El principio de la responsabilidad: ensayo de una ética para la civilización tecnológica. Barcelona: Editorial Herder, 1995. 


\section{SUSTENTABILIDADE E ATIVISMO JUDICIAL: A SUSTENTABILIDADE COMO PRINCÍPIO SISTÊMICO ORIENTADOR DAS DECISÕES JUDICIAIS}

Com a superação do positivismo, restou clara a insuficiência do modelo de sistema hermético. O dogma da completude ${ }^{39}$ caiu por terra e passou-se a admitir que as normas jurídicas resguardam alguma abertura - as denominadas franjas - a qual, nos casos difíceis, poderia ser usada pelo magistrado para construir a norma compatível com essas situações complexas, o que denota, de forma inquestionável, o poder criativo do juiz ${ }^{40}$.

A era pós-positivista ${ }^{41}$ resgata a importância dos princípios, que reaparecem reivindicando uma qualidade normativa de certa forma inovadora ${ }^{42}$. De meras premissas que estampavam enunciados amplos, fluídos e insertos de valores esparsos, passam a ser tornar diretrizes normativas integrantes do sistema jurídico.

A diferença entre regras e princípios foi proposta por Dworkin ${ }^{43}$. $\mathrm{O}$ autor sustenta que princípios possuiriam uma dimensão de peso, sendo sua colisão resolvida segundo a importância de cada um deles no caso concreto. Já as regras, por sua vez, teriam estrutura lógica diferenciada dos princípios, sendo aplicadas caso estivessem presentes todos os seus pressupostos fáticos. Tratase do que Dworkin intitula de "tudo ou nada" (all or nothing), ou seja, se houvesse conflito entre regras jurídicas, este seria resolvido no âmbito da validade.

Já Alexy ${ }^{44}$ propõe uma teoria mista de direitos fundamentais, sustentando que podem se caracterizar por meio de regras ou princípios, mas que a diferença entre as duas espécies normativas seria qualitativa. Os princípios relevantes para as decisões que envolvem direitos fundamentais seriam aqueles que poderiam ser utilizados argumentativamente de forma substancial. Segundo o autor, princípios podem ser compreendidos como:

Normas que ordenam que algo seja realizado na maior medida possível, dentro das possibilidades jurídicas e reais existentes. Portanto, os princípios são mandados de otimização, que estão caracterizados pelo fato de que podem ser cumpridos em diferentes graus, e que a medida devida de seu cumprimento não só depende das possibilidades reais, como também das jurídicas ${ }^{45}$.

Com a pós-modernidade, a tendência é pensar os princípios cada vez mais como constituintes lógicos que orientam os processos de comunicação e de argumentação. Consequentemente, cada vez mais os princípios são empregados como princípios racionais, e não causais, da realidade. Por isso mesmo a tendência está em se conceber que, no caso dos princípios práticos, eles decorrem de padrões de escolhas contextualizadas, geralmente determinadas pelo estágio moral da própria sociedade que se coloca a questão acerca dos princípios ${ }^{46}$.

39 "[...] princípio de que o ordenamento jurídico seja completo para fornecer ao juiz, uma solução sem recorrer à equidade $[\ldots] "$ ". BOBBIO, Norberto. Teoria do ordenamento jurídico. Brasília: Universidade de Brasília, 1999, p. 19.

40 CHAMON JUNIOR, Lúcio Antônio. Teoria geral do direito moderno: por uma reconstrução crítico discursiva na alta modernidade. Rio de Janeiro: Lúmen Júris, 2003, p. 52.

41 Compreende-se esse período pela superação dialética da antítese entre positivismo e jusnaturalismo, com a distinção das normas jurídicas em regras e princípios, tendo como conteúdo os valores (CHAMON JUNIOR, Lúcio Antônio. Teoria geral do direito moderno: por uma reconstrução crítico discursiva na alta modernidade. Rio de Janeiro: Lúmen Júris, 2003, p. 65).

42 BARROSO, Luís Roberto. Fundamentos teóricos e filosóficos do novo direito constitucional brasileiro: pós-modernidade, teoria crítica e pós-positivismo. Revista Diálogo Jurídico, Salvador, CAJ - Centro de Atualização Jurídica, v. 1, n. 6, setembro, p. 1-32, 2001. Disponível em: <http://www.direitopublico. com.br/ pdf_6/dialogo-juridico-06-setembro-2001-luis-roberto-barroso.pdf > Acesso em: 8 mar. 2013.

43 DWORKIN, Ronald. Levando os direitos a sério. Tradução de Nelson Boeira. São Paulo: Martins Fontes, 2002, p. 76.

44 ALEXY, Robert. Teoria de los derechos fundamentales. Madrid: Centro de Estudios Constitucionales, 1993, p. 83.

45 ALEXY, Robert. Teoria de los derechos fundamentales. Madrid: Centro de Estudios Constitucionales, 1993, p. 86-87.

46 GALUPPO. Marcelo Campos. Os princípios jurídicos no Estado Democrático de Direito: ensaio sobre o modo de sua aplicação. Revista de Informação Legislativa. Brasília, a.36, n. 143, jul./set. 1999, p. 200. 
Diante desse panorama, a atividade jurisdicional passa a ganhar maior relevo, já que o juiz não está mais adstrito aos raciocínios dedutivos, à lógica dos silogismos, na resolução dos casos. Ao contrário, o magistrado passa a usufruir de maior liberdade para proferir suas decisões, que poderão ser fundamentadas nos princípios. Registre-se que os princípios, para terem validade, não precisam estar positivados de forma expressa na ordem jurídica. Não há uma enumeração taxativa, o que permite maior maleabilidade ao sistema jurídico que pode agregá-los a qualquer tempo, sinalizando um movimento jurídico de incorporação de valores e que procura refletir os anseios da sociedade. Segundo Freitas ${ }^{47}$, o sistema jurídico contemporâneo consiste em:

[...] uma rede axiológica e hierarquizada de princípios gerais e tópicos, de normas e de valores jurídicos, cuja função é a de, evitando ou superando antinomias, dar cumprimento aos princípios e objetivos fundamentais do Estado Democrático de Direito, assim como se encontram consubstanciados, expressa ou implicitamente, na lei maior.

Deve-se compreender sustentabilidade como princípio geral e sistêmico, já que a ausência de previsão normativa explícita não se antepõe como pressuposto insuperável ao seu reconhecimento. É que a sustentabilidade não surge como realidade tópica, resultado de referência em dispositivo específico e isolado; ao contrário, nela se aninha um princípio sistêmico, que se funda e decorre da leitura conjunta e do diálogo multidirecional das normas que compõem a totalidade do vasto mosaico constitucional ${ }^{48}$. Pontes de Miranda ${ }^{49}$ já afirmava:

\begin{abstract}
Ninguém deve improvisar princípios jurídicos, como ninguém pode fazer regras econômicas, políticas ou morais. É com tijolo que se constroem casas, e não com palavras. É das relações sociais que se tiram os princípios, de modo que entre as leis e eles pode haver paralelismo e a ineficácia daquelas será proporcional à discordância entre uns e outros. Na vida, toda a aplicação tenderá para reduzir as leis aos princípios e a perfectibilidade está em formulá-las o mais próximas deles que for possível. Todos os princípios têm conteúdo especial (ético, político, econômico, etc.), ou geral (social), e seria preciso modificar a substância social para modificar, ou para suprimi-los. É pela indução que, das soluções mostradas nas relações que se observam, pode tirar-se o princípio; depois, pela dedução, aplicar-se-á aos casos análogos.
\end{abstract}

Ademais, a sustentabilidade é decorrente do primado da dignidade humana que se irradia em diversos outros princípios, como: da obrigatoriedade de proteção ambiental; da prevenção ou da precaução; da ampla informação ambiental; da função social dos contratos e da propriedade; do poluidor-pagador; da compensação; da responsabilidade; da solidariedade, da educação ambiental. Decorre o princípio da sustentabilidade, ainda da combinação de outras normas (princípios e regras) insertas na mesma carta constitucional, em tratados e convenções por ela recepcionados e, ademais, decorrentes legislação infraconstitucional pertinente.

Os princípios importam em tal a generalidade e a abstração que propiciam a asserção de que sua interpretação deve ser ampla, móvel e evolutiva, o que implica dizer que não comportam encarceramento, rigidez. Cada caso, ao ser julgado, deve ser analisado como um novo caso, irrepetível como os fatos da história, único, que requer a interpretação das normas de todo o sistema jurídico de forma sistematizada e não apenas de forma isolada e literal, também considerando e sopesando princípios e, especialmente, os valores sociais e jurídicos contemporâneos, para apresentar solução que se apresente como a única adequada e justa que o caso comporta, e que guarde aceitação racional segundo entendimento do cidadão médio ${ }^{50}$.

A sustentabilidade encontra-se habitualmente associada a um conteúdo ambiental, mas como salientado no tópico anterior, essa é apenas uma caracterização primária, pois o meio ambiente é apenas um de seus alicerces fundamentais. A sustentabilidade pode ser compreendida como um comando constitucional abrangente, a orientar as demais normas jurídicas e as decisões judiciais:

47 FREITAS, Juarez de. A interpretação sistemática do direito. 4. ed. São Paulo: Malheiros, 2004, p. 69.

48 PINTO COELHO, Saulo de Oliveira; ARAÚJO, André Fabiano Guimarães de. A sustentabilidade como princípio constitucional sistêmico e sua relevância na efetivação interdisciplinar da ordem constitucional econômica e social: para além do ambientalismo e do desenvolvimentismo. Revista da Faculdade de Direito de Uberlândia, Uberlândia, v. 39, n. 1, p. 261-291, 2011. Disponível em: <http://www. seer.ufu. br/index.php/revistafadir/article/view/18499/9916>. Acesso em: 8 mar. 2013.

49 PONTES DE MIRANDA, Francisco Cavalcanti. Sistema de ciência positiva do direito. 2. ed., vol. IV. Rio de Janeiro: Editor Borsoi, 1972, p. 221-222.

50 OLIVEIRA, Marcelo Andrade Cattoni de. Tutela jurisdicional e estado democrático de direito. Belo Horizonte: Del Rey, 1997. 
Partindo da Constituição Federal e irradiando-se por todo o ordenamento jurídico infraconstitucional, a sustentabilidade como princípio constitucional possui uma estruturação fundamentalmente interdisciplinar e transdisciplinar [...]. Compreender a sustentabilidade como um princípio constitucional não somente ambiental, mas também como princípio constitucional interdisciplinar, social, empresarial, administrativo e econômico, constitui uma importante tarefa da dogmática jurídica contemporânea, em busca da efetividade das idéias que gravitam no entorno da solidariedade e da dignidade como balizas do Estado Democrático de Direito. Nesse sentindo, busca-se evidenciar a sustentabilidade em seu caráter sistêmico-constitucional, o que implica uma compreensão interdisciplinar desse principio basilar não somente no viés ambiental, mas também na perspectiva econômico-empresarial e social, numa visão que se quer integrada e integrativa desses âmbitos, quando alçados ao plano constitucional ${ }^{51}$.

Ao se compreender sustentabilidade como princípio, sua importância se evidencia no ordenamento jurídico, o que justificaria o embasamento e a fundamentação de decisões do Poder Judiciário, a fim de dar efetividade ao texto constitucional. Manifesta-se a sustentabilidade como base fundamental dos direitos, sendo eles constitucionais e organizacionais, além de guardar estreita relação tutelar com o direito ao meio ambiente e ao primado da preservação dos bens naturais que possibilitam a sobrevivência digna e equilibrada dos seres humanos ${ }^{52}$.

O princípio da sustentabilidade ambiental é corolário do princípio do não retrocesso na seara ambiental. Ora, a sustentabilidade só é possível se guiada por ações permanentes e responsáveis, seja do Estado, seja dos particulares. Nessa ordem de ideias, a participação do juiz é fundamental ao atribuir, a cada caso concreto, a possibilidade de efetivação dos ideais sustentáveis. Busca-se um novo horizonte hermenêutico ${ }^{53}$, que exige do juiz uma participação efetiva na construção de decisões comprometidas com o crescimento sustentável.

Ao tratar do meio ambiente, por exemplo, deve-se pensar que não apenas as leis ambientais têm a função de garantir a sustentabilidade ambiental. A necessária proteção ao meio ambiente exige atuação mais direta e eficaz, que pode se dar a partir da construção de uma decisão que exalte o caráter de sustentabilidade a ser observado em todas as relações jurídicas. Dessa forma, deve-se incitar também a participação do cidadão para a implementação dessas metas. Nesse sentido: "La participation et l'information du public permet de garantir un niveau de protection sui sant grâce à un contrôle citoyen permanent" ${ }^{\prime 54}$.

A reflexão de Ricouer ${ }^{55}$ denota a insuficiência da resposta dogmática clássica e a crise no direito contemporâneo que demanda a busca de novas respostas e decisões fora do âmbito restrito de aplicação da lei. Trata-se da construção de uma concepção ética e solidarista que se caracteriza pela subsistência de duas responsabilidades não excludentes ligadas à sustentabilidade: a responsabilidade do bem - que obriga a preservação - e a responsabilidade do melhor - que determina o progresso e o aperfeiçoamento qualitativo da vida humana.

A Constituição da República de 1988 é esclarecedora e não deixa margens para dúvidas: o modelo político instituído no Brasil tem, como um de seus "objetivos fundamentais", o "desenvolvimento nacional" e a erradicação da "pobreza" (artigo 30, II e III), norte esse que igualmente informa a necessária cooperação com outras nações, que observará, entre outros princípios, "o progresso da humanidade" (artigo 40, IX). Ademais, dispõe o artigo 225 da CR/88:

51 PINTO COELHO, Saulo de Oliveira; ARAÚJO, André Fabiano Guimarães de. A sustentabilidade como princípio constitucional sistêmico e sua relevância na efetivação interdisciplinar da ordem constitucional econômica e social: para além do ambientalismo e do desenvolvimentismo. Revista da Faculdade de Direito de Uberlândia, Uberlândia, v. 39, n. 1, 2011, p. 263. Disponível em: <http://www.seer. ufu.br/ index.php/revistafadir/article/view/18499/9916>. Acesso em: 8 mar. 2013.

52 MILARÉ, Edis. Direito do ambiente: doutrina, jurisprudência, glossário. 5. ed. São Paulo: Revista dos Tribunais, 2007.

53 CALDEIRA, Ana Paula Canoza. A interconexão entre o direito e o meio ambiente sob a ótica da hermenêutica. In: FLORES, Nilton Cesar Flores (Org.). A sustentabilidade ambiental em suas múltiplas faces. São Paulo: Editora Millennium, 2012.

54 PRIEUR, Michel. De I'urgente nécessité de reconnaître le principe de non régression en droit de 'environnement In: OLIVEIRA, Carina Costa; SAMPAIO, Romulo Silveira R. (Org.). A economia verde no contexto do desenvolvimento sustentável: a governança dos atores públicos e privados. Rio de Janeiro: FGV, Direito Rio, 2011, p. 255. Disponível em: <http://bibliotecadigital.fgv.br/dspace/ bitstream/handle/10438/10353/A\%20Economia\%20Verde\%20no\%20Contexto\%20do\%20Desenvolvimento\%20Sustent\%C3\%A1vel.pdf?sequence=1>. Acesso em: 8 mar. 2013.

55 RICOUER, Paul. Le juste. Paris: Éditions du Seiu, 199l, p. 43. 
Todos têm direito ao meio ambiente ecologicamente equilibrado, bem de uso comum do povo e essencial à sadia qualidade de vida, impondo-se ao Poder Público e à coletividade o dever de defendê-lo e preservá-lo para as presentes e futuras gerações.

Ao abraçar o "progresso da humanidade" na forma de conceito informador de seu sistema, o texto constitucional demostra uma aspiração constitucionalizada de melhoria universal: progresso planetário que inclui seres humanos e todas as bases da vida na terra. A sobrevivência atual e futura da humanidade depende dessa prosperidade. Por progresso haverá de se entender não apenas prosperidade material, pois, ao certo, inclui a ampliação e o fortalecimento permanente do arcabouço de antigos e novos valores intangíveis, muitos deles coletivos por excelência e subprodutos da ética da solidariedade e da responsabilidade. A prosperidade imaterial coaduna-se com o conteúdo da sustentabilidade que tem caráter etéreo e impalpável, mas de indiscutível realidade ${ }^{56}$.

No paradigma liberal, o isolamento político e social do Judiciário reduziu a sua atuação e a aferição de sua legitimidade se dava a priori. No entanto a atividade judicial na contemporaneidade revela que sua legitimidade é identificada com base na adequação da conduta judicial aos princípios constitucionais. Este pensamento indica que, para resolver o caso de forma adequada, há que se considerar não apenas a regra positiva, mas os princípios jurídicos que devem ser aplicados:

[...] nos limites e nos contornos das circunstâncias fáticas (adequabilidade), o que não quer dizer que eles sejam propriamente determinados por essas circunstâncias. Antes, eles funcionam como pressupostos que orientam os processos de aplicação das regras e dos próprios princípios jurídicos, que transferem correção a esses processos ${ }^{57}$.

O Estado Democrático de Direito não aceita mais a postura desidiosa e passiva do Judiciário. O juiz deve concretizar o significado das declarações constitucionais e, nesse sentido, não pode executar uma função apenas jurídica, técnica e secundária, mas, ao contrário, há de comprometerse a desempenhar um papel ativo. É chamado a contribuir para a efetivação dos princípios constitucionais, buscando dar-Ihes densidade real e concreta. $O$ magistrado, atento às demandas no mundo contemporâneo, deve, ao julgar o caso, não apenas aplicar o comando da lei, mas avaliar as repercussões sociais, políticas, econômicas, ambientais e outras que a decisão irá surtir.

É o exercício ativo da atividade jurisdicional, não apenas conformando suas decisões com as regras legais, mas buscando soluções que se coadunem com os valores condutores do Estado Democrático de Direito. Na verdade, as atividades política e judicial estão intimamente ligadas ao Estado de direito. Nesse sentido:

Otro aspecto de la politización del juez está en el hecho de que las constituciones modernas contemplan normas de contenido poroso, a ser complementado por la práxis. Y el Poder Legislativo derivado, a su vez, en muchas situaciones, no sólo no se esfuerza para rellenar el vacío, sino prima por seguir la misma técnica de la legislación abierta, indeterminada. Incapaz de solucionar algunos mega-conflictos modernos, muchas veces el legislador acaba atribuyendo al Poder Judicial la responsabilidad de moldar la norma final aplicable. El Poder Judicial no sólo pasó a solucionar los conflictos intersubjetivos de intereses, según el modelo liberal individualista, sino también a actuar como órgano calibrador de tensiones sociales, solucionando conflictos de contenido social, político y jurídico, además de implementar el contenido promocional del Derecho contenido en las normas constitucionales y en las leyes que consagran derechos sociales. De cualquier forma, "esa politización del juez, que es innegable dentro del Estado Constitucional de Derecho, concebido como fuente y límite del derecho, no puede, sin embargo, llegar al extremo de permitirle la sustitución de la racionalidad jurídica por la racionalidad política. Ese es hoy un problema que ronda la legitimación democrática de la jurisdicción [...]"158.

A sustentabilidade pode ser compreendida como uma proposta que pretende a implementação de um desenvolvimento ético e solidário, e não apenas visando a um horizonte de desenvolvimento técnico dissociado da implementação dos primados constitucionais. Nesse sentido, o Poder Judiciário não pode se manter silente e distante, já que a participação do juiz é fundamental para dar efetividade a metas de sustentabilidade. As decisões judiciais podem ser instrumentos de implementação de

56 BENJAMIN, Antônio Herman. O Estado teatral e a implementação do direito ambiental. In: Congresso Internacional de Direito Ambiental, 7, 2004, São Paulo. Anais... São Paulo: IMESP, 2004, p. 11.

57 GALUPPO. Marcelo Campos. Os princípios jurídicos no Estado Democrático de Direito: ensaio sobre o modo de sua aplicação. Revista de Informação Legislativa. Brasília, a.36, n. 143, jul./set. 1999, p. 200, p. 201.

58 FERRAJOLI, Luigi. Justicia penal y democracia. Jueces para la Democracia, Madrid, n. 4, set. 1988, p. 5. 
práticas sustentáveis por meio, por exemplo, da revisão dos contratos que não atentam para o desenvolvimento sustentável. A sustentabilidade assume a condição de um dos mecanismos para a afirmação efetiva de um direito constitucional inclusivo, solidário e altruísta.

Admitir a sustentabilidade como princípio implica incorporar de modo definitivo ao horizonte da intervenção transformadora do homem (mundo das necessidades atuais) o compromisso com a perenização da vida. Propõe-se a adoção da sustentabilidade como norteadora de todo o agir humano de forma a transformar suas ações em resultados sólidos e efetivos para garantir o seu verdadeiro objetivo.

A sustentabilidade não pode ser concebida como mera opção, há de ser adotada como orientação necessária e irrefutável, a fim de se conservar mais capital natural para futuras gerações e, portanto, todos os mecanismos de sua implementação devem ser envidados, concentrando todas as esferas do Poder para a assunção dessa meta.

Faz-se necessário um giro na perspectiva de compreensão do mundo pelo ser humano. As relações privadas contemporâneas não podem ser compreendidas apenas como palco de satisfação de necessidades e desejos imediatos das partes, mas também espaço para que se alcance o desenvolvimento sustentável.

As exigências da sustentabilidade envolvem a cooperação entre os Estados, entre o Estado e os cidadãos ou os grupos da sociedade civil na promoção de políticas públicas (econômicas, educativas, de ordenamento), como também o dever de adoção de comportamentos públicos e privados focados nessa meta, de modo a dar expressão concreta à assunção de condutas comprometidas com o bem-estar das gerações futuras. Nesse raciocínio, a atuação jurisdicional é crucial para o fomento de ações sustentáveis, já que pode servir como limite de promoção à atuação do indivíduo. A autonomia passa então a ser conformada por metas de sustentabilidade, o que leva a ideia do Estado de Direito do Ambiente, entendido por Canotilho ${ }^{59}$ como:

\begin{abstract}
Estado de direito do ambiente quer dizer indispensabilidade das regras e princípios do Estado de direito para se enfrentarem os desafios impostos pelos desafios da sustentabilidade ambiental. [...] Não nos admirará também a inseparabilidade do Estado de ambiente do princípio democrático. A afirmação desta nova dimensão do Estado pressupõe o diálogo democrático, exige instrumentos de participação, postulado princípio da cooperação com a sociedade civil. O Estado de ambiente constrói-se democraticamente de baixo para cima; não se dita em termos iluminísticos e autoritários de cima para baixo.
\end{abstract}

\title{
CONSIDERAÇÕES FINAIS
}

Procurou-se demonstrar a crescente importância do ativismo judicial, como uma atuação consciente, politizada e criativa do juiz no sentido de aplicar, a cada caso concreto, uma decisão que se coadune com a principiologia pretendida pelo Estado Democrático de Direito.

A possibilidade de uma atuação mais livre e politizada do magistrado é demonstrada por meio da inclusão de cláusulas gerais no ordenamento jurídico. A cláusula geral, ao criar aberturas no ordenamento, reconfigura-o de modo a permitir, na aplicação do direito ao caso concreto, um conteúdo de dinamicidade social. Essa técnica legislativa permite a conjugação, pelo magistrado, dos elementos predeterminados pela lei com elementos ainda não presentes na legislação.

Demonstrou-se que a ideia de completude do sistema jurídico de regras é obsoleta, já que poderia propiciar, por ausência de previsão legal, a efetiva tutela dos interesses dos sujeitos. E mais, sustentou-se que a decisão judicial deve revelar a adoção de práticas de implementação de princípios e valores pretendidos pela sociedade.

Nesse contexto, a sustentabilidade, na sua multiplicidade conceitual, é compreendida como um princípio sistêmico a orientar as decisões judiciais e a legitimar a atuação criativa do juiz, principalmente se considerada a responsabilidade do homem com as gerações futuras. Assim, a atuação jurisdicional é fundamental para o fomento de ações sustentáveis, conformando a autonomia, de certa forma, às metas de sustentabilidade.

59 CANOTILHO, José Joaquim Gomes. Estado de direito. Lisboa: Gradiva, 1999. (Colecção Cadernos

Democráticos, v. 7), p. 45. 
Como princípio jurídico, evidencia-se o conteúdo de generalidade e abstração assumido pela sustentabilidade no atual sistema, bem como sua importância, a propiciar uma interpretação ampla, móvel e evolutiva de seu conceito. Defende-se que sua promoção depende também da atuação do Poder Judiciário, que poderá conferir, sempre que possível, a cada caso concreto, uma decisão comprometida com a efetivação do princípio da sustentabilidade.

Incorporar tal conceito como princípio orientador do ordenamento jurídico implica a aceitação definitiva de que qualquer intervenção transformadora do homem deve ter o compromisso com a perenização da vida.

As relações privadas, no contexto atual, não podem ser compreendidas tão somente como espaço de satisfação de necessidades e desejos imediatos dos particulares, mas hão de ser compreendidas também como palco para que se alcance o desenvolvimento sustentável.

\section{REFERÊNCIAS}

ALEXY, Robert. Teoria de los derechos fundamentales. Madrid: Centro de Estudios Constitucionales, 1993.

AMARAL, Francisco. Transformações dos sistemas positivos a descodificação do direito civil brasileiro. $\mathbf{O}$ Direito, Lisboa, ano 129, v. I, n. II, 1997.

BARROSO, Luís Roberto. Fundamentos teóricos e filosóficos do novo direito constitucional brasileiro: pós-modernidade, teoria crítica e pós-positivismo. Revista Diálogo Jurídico, Salvador, CAJ - Centro de Atualização Jurídica, v. 1, n. 6, setembro, p. 1-32, 2001. Disponível em: http://www.direitopublico.com. br/pdf_6/dialogo-juridico-06-setembro-2001-luis-roberto-barroso.pdf. Acesso em: 8 mar. 2013.

BARROSO, Luís Roberto. Judicialização, ativismo judicial e legitimidade democrática. Revista de Direito do Estado, Rio de Janeiro, n. 13, p. 71-91, jan./mar. 2009.

BENJAMIN, Antônio Herman. O Estado teatral e a implementação do direito ambiental. In: Congresso Internacional de Direito Ambiental, 7, 2004, São Paulo. Anais... São Paulo: IMESP, 2004.

BOBBIO, Norberto. Teoria do ordenamento jurídico. Brasília: Universidade de Brasília. 1999.

BRUNDTLAND, Gro Harlem. Nosso futuro comum: comissão mundial sobre meio ambiente e desenvolvimento. 2. ed. Rio de Janeiro: Fundação Getúlio Vargas, 1991. Disponível em: <http://pt.scribd.com/ doc/12906958/Relatorio-Brundtland-Nosso-Futuro-Comum-Em-Portugues>. Acesso em: 8 mar. 2013.

CALDEIRA, Ana Paula Canoza. A interconexão entre o direito e o meio ambiente sob a ótica da hermenêutica. In: FLORES, Nilton Cesar Flores (Org.). A sustentabilidade ambiental em suas múltiplas faces. São Paulo: Editora Millennium, 2012.

CANARIS, Claus-Wilheim. Pensamento sistemático e conceito de sistema na ciência do direito. 2. ed. Lisboa: Fundação Calouste Gulbenkian, 1996.

CANOTILHO, José Joaquim Gomes. Protecção do ambiente e direito de propriedade: crítica de jurisprudência ambiental. Coimbra: Coimbra Editora, 1995.

CANOTILHO, José Joaquim Gomes. Estado de direito. Lisboa: Gradiva, 1999. (Coleção Cadernos Democráticos, v. 7).

CAPELLETTI, Mauro. Juízes legisladores? Tradução de Carlos Alberto Álvaro de Oliveira. Porto Alegre: Sergio Antônio Fabris Editor, 1999.

CAPRA, Fritjof. O Ponto de mutação: a ciência, a sociedade e a cultura emergente. 25. ed. São Paulo: Cultrix, 1982.

CARVALHO NETTO, Menelick de. Requisitos pragmáticos da interpretação jurídica sob o paradigma do estado democrático de direito. Revista de Direito Comparado, Belo Horizonte, v. 3. 1999, p. 473-486.

CHALIFOUR, Nathalie J. Land use law for sustainable development. Cambridge University Press: Cambridge, 2007. 
CHAMON JUNIOR, Lúcio Antônio. Teoria geral do direito moderno: por uma reconstrução crítico discursiva na alta modernidade. Rio de Janeiro: Lúmen Júris, 2003.

DEL NERO, João. Interpretação realista do direito e seus reflexos na sentença. São Paulo: RT, 1987.

DWORKIN, Ronald. Levando os direitos a sério. Tradução de Nelson Boeira. São Paulo: Martins Fontes, 2002.

ENGLES, Friedrich. A origem da família, da propriedade privada e do estado. Tradução Ruth M. São Paulo: Klauss Centauro Editora, 2009.

FARIA, José Henrique de. Por uma teoria crítica da sustentabilidade. In: NEVES, Lafaiete Santos (Org.). Sustentabilidade: anais de textos selecionados do $\mathrm{V}$ seminário sobre sustentabilidade. Curitiba: Juruá Editora, 2011.

FERRAJOLI, Luigi. Justicia penal y democracia. Jueces para la Democracia, Madrid, n. 4, set. 1988.

FIÚZA, César. Crise e interpretação do direito civil da escola da exegese às teorias da argumentação. In: FIÚZA, César; SÁ, Maria de Fátima Freire de; NAVES, Bruno Torquato de Oliveira (Coords.). Direito civil: atualidades. Belo Horizonte: Editora Del Rey, 2004

FREITAS, Juarez de. A interpretação sistemática do direito. 4. ed. São Paulo: Malheiros, 2004.

GALUPPO. Marcelo Campos. Os princípios jurídicos no Estado Democrático de Direito: ensaio sobre o modo de sua aplicação. Revista de Informação Legislativa. Brasília, a.36, n. 143, p. 191-209, jul./ set. 1999.

HANSEN, Gilvan Luiz. A sociedade de consumo e o paradoxo da proteção ambiental. In: FLORES, Nilton Cesar (Org.). A sustentabilidade ambiental em suas múltiplas faces. São Paulo: Editora Millennium, 2012.

IRTI, Natalino. L'età della decodificazione. 4. ed. Milano: Giufrrè, 1999.

JONAS, Hans. El principio de la responsabilidad: ensayo de una ética para la civilización tecnológica. Barcelona: Editorial Herder, 1995.

JORGE JUNIOR, Alberto Gosson. Cláusulas gerais no novo código civil. São Paulo: Saraiva, 2004.

LARENZ, Karl. Metodologia da ciência do direito. Lisboa: Fundação Calouste Gulbenkian, 1997.

LEAL, Rosemiro Pereira. Teoria processual da decisão jurídica. São Paulo: Landy, 2002.

LEAL, Rosemiro Pereira. Isonomia processual e igualdade fundamental a propósito das retóricas ações afirmativas. Revista Jurídica Unijus, Uberaba, v. 6, 2003.

LORENZETTI, Ricardo Luis. Fundamentos do direito privado. Tradução Vera Maria Jacob de Fradera. São Paulo: Revista dos Tribunais, 1998.

MARTINS-COSTA, Judith. A boa-fé no direito privado: sistema e tópica no processo obrigacional. São Paulo: Editora Revista dos Tribunais, 1999.

MENEZES CORDEIRO, Antônio Manuel da Rocha e. Da boa-fé no direito civil. Coimbra: Almedina, 2001.

MILARÉ, Edis. Direito do ambiente: doutrina, jurisprudência, glossário. 5 ed. São Paulo: Revista dos Tribunais, 2007.

OLIVEIRA, Marcelo Andrade Cattoni de. Tutela jurisdicional e estado democrático de direito. Belo Horizonte: Del Rey, 1997.

PINTO COELHO, Saulo de Oliveira; ARAÚJO, André Fabiano Guimarães de. A sustentabilidade como princípio constitucional sistêmico e sua relevância na efetivação interdisciplinar da ordem constitucional econômica e social: para além do ambientalismo e do desenvolvimentismo. Revista da Faculdade de Direito de Uberlândia, Uberlândia, v. 39, n. 1, p. 261-291, 2011. Disponível em: <http://www.seer.ufu.br/index. php/revistafadir/article/view/18499/9916>. Acesso em: 8 mar. 2013. 
PODESTÁ, Fábio Henrique. A ideologia das decisões judicias em matéria de contratos. In: HIRONAKA, Giselda Maria Fernandes Novaes. A outra face do judiciário: decisões inovadoras e mudanças de paradigmas. Belo Horizonte: Editora Del Rey, 2005.

PONTES DE MIRANDA, Francisco Cavalcanti. Sistema de ciência positiva do direito. 2. ed., vol. IV. Rio de Janeiro: Editor Borsoi, 1972.

PRIEUR, Michel. De I'urgente nécessité de reconnaître le principe de non régression en droit de 'environnement In: OLIVEIRA, Carina Costa; SAMPAIO, Romulo Silveira R. (Org.). A economia verde no contexto do desenvolvimento sustentável: a governança dos atores públicos e privados. Rio de Janeiro: FGV, Direito Rio, 2011. Disponível em: <http://bibliotecadigital. fgv.br/dspace/bitstream/ handle/10438/10353/A\%20Economia\%20Verde\%20no\%20Contexto\%20do\%20Desenvolvimento\%20 Sustent\%C3\%A1vel.pdf?sequence=1>. Acesso em: 8 mar. 2013.

RICOUER, Paul. Le juste. Paris: Éditions du Seiu, 1991.

SÁ, Maria de Fátima Freire de. Direito de morrer. Belo Horizonte: Del Rey, 2001.

SILVA, Ovídio A. Baptista da. Processo e Ideologia: o paradigma racionalista. Rio de Janeiro: Forense, 2004.

SOUZA, Luiz Sérgio Fernandes de. 0 papel das ideologias no preenchimento das lacunas de direito. São Paulo: RT, 1993.

VIEHWEG, Theodor. Tópica e jurisprudência. Brasília: Imprensa Nacional, 1979. 